\title{
IDENTIFIKASI KAWASAN CAGAR BUDAYA SITUS KERAJAAN ISLAM MATARAM DI PLERET, BANTUL DENGAN PENDEKATAN SISTEM INFORMASI GEOGRAFIS (SIG)
}

\author{
M. Rosidi, A. Darmawan, dan K. Rahmawati \\ Mahasiswa S2 Ilmu Lingkungan Fakultas Geografi Universitas Gadjah Mada \\ rosidi.muhammad@gmail.com
}

\begin{abstract}
Abstrak : Kerajaan Mataram merupakan salah satu kerajaan besar dalam sejarah kerajaan-kerajaan di Indonesia. Banyak peninggalan sejarah yang sangat bermanfaat untuk pembangunan dan ilmu pengentahuan, namun jejak-jejak sejarah semakin hilang karena perubahan penggunaan lahan saat ini. Untuk itu telah banyak metode dan pendekatan untuk menggali peninggalan-peninggalan sejarah terlebih untuk merekonstruksi suatu kerajaan, dalam hal ini adalah Kerajaan Mataran Islam di Pleret Bantul. Salah satu pendekatan yang digunakan dalam kajian ini adalah menggunakan sistem informasi geografis. Kajian ini bertujuan melihat sebaran spasial situs-situs sejarah yang telah ditemukan dan menghubungkan dengan penggunaan lahan eksisting sehingga didapatkan prediksi kawasan Kerajaan Mataram Islam dahulu dan melihat kebijakan daerah. Metode yang dilakukan adalah dengan melakukan kajian literatur, wawancara dengan masyarakat dan tokoh masyarakat, kajian spasial berdasarkan citra resolusi tinggi dengan melakukan survei di lapangan, dan juga menghubungkan dengan kebijakan daerah terhadap kawasan tersebut. Berdasarkan analisa yang dilakukan, distribusi spasial kawasan terhadap rekonstruksi Kerajaan Mataram Islam di Pleret dapat dilihat dengan menggunakan pendekatan sistem informasi geografis, hal ini juga didukung toponimi nama-nama dusun di daerah tersebut. Hanya saja dalam kebijakan daerah masih kurangnya sinkronisasi program antar SKPD sehigga keberadaan situs kerajaan ataupun cagar budaya yang ada belum menjadi perhatian khusus untuk keberlanjutan penelusuran jejak-jejak sejarah kerajaan tersebut. Untuk pendekatan kawasan maka sistem informasi geografis dan penginderaan jauh cukup optimal dalam pemanfaatannya didalam mendukung pemetaan keberadaan situs-situs sejarah sehingga didapatkan kaitan satu sama lain.
\end{abstract}

Kata kunci: identifikasi, situs, sistem informasi geografis

\begin{abstract}
Mataram Kingdom was one of great kingdoms in Indonesia. Many historical remains can be useful for development and science, although the historical traces are vanishing as a result of change in present land use. Many methods and approaches can be used to reconstruct historical remains of a kingdom, in this case Islamic Mataram Kingdom in Pleret, Bantul. One of the approaches used in this study is geographic information system. The study is aimed to find out the distribution of historical sites and put them into existing land use to predict the area of Islamic Mataram Kingdom and regional policy. Methods used are literature study, interview with community and their leaders, spatial study based on high resolution image combined with field survey, as well as regional policy on those areas. Based on the analysis, area spatial distribution for reconstruction of Islamic Mataram Kingdom in Pleret, can be seen by geographic information system approach. It is also supported by the toponymy of sub-village in the region. On the other hand, the regional policy is shown by lack of synchronization of regional offices so that the existence of cultural property has not been the main focus for further exploration in locating historical traces. Geographic information system and remote sensing is quite optimal in supporting the mapping of historical sites related to each other.
\end{abstract}

Keywords: identification, site, geographic information system

\section{Latar Belakang}

Kerajaan Mataram merupakan salah satu kerajaan besar di khazanah sejarah nusantara selain Majapahit dan Singasari. Kerajaan Mataram mengalami pasang surut baik Mataram Hindu maupun Mataram Islam. Perpindahan kekuasaan dan lokasi kerajaan selama ini belum banyak yang dikaji, terutama dalam kajian spasial ataupun keruangannya. Salah satu lokasi eks Kerajaan Mataram Islam yang belum banyak dikaji adalah di wilayah Pleret. Wilayah Pleret di Kabupaten Bantul tidak bisa dipisahkan dari perkembangan sejarah Kerajaan Mataram Islam.
Kerajaan Mataram Islam yang pada awal mula didirikan oleh Panembahan Senopati (R. Danang Sutawijaya) pada tahun $1587 \mathrm{M}$ beribukota di Kotagede. Kemudian seiring peralihan kekuasaan pada keturunannya, ibukota pernah berpindah. Mataram Islam sempat beribukota di Karta ketika masa pemerintahan Sultan Agung Hanyokrokusumo (raja ke-3 dinasti Mataram Islam) dan mulai ditempati pada tahun $1618 \mathrm{M}$. Masa selanjutnya yaitu Amangkurat I penerus Sultan Agung Hanyokrokusumo, ibukota dipindahkan ke Pleret (1649 M). 


\section{Lokasi Penelitian}

Lokasi penelitian berada di Dusun Kedaton, Kanggotan, Pungkuran, Keputren, Kauman, dan Karta yang berada di Desa Pleret dan Desa Wonokromo, Kecamatan Pleret, Kabupaten Bantul, Yogyakarta.

\section{Metode Penelitian}

Penelitian ini menggunakan data primer dan data sekunder untuk mendukung analisis dalam menentukan kawasan cagar budaya menggunakan sistem informasi geografis. Data primer diperoleh melalui wawancara dan survei langsung ke lapangan, sedangkan data sekunder didapatkan dari kajian literatur penelitian sebelumnya dan data-data yang sudah ada.
Metode analisis yang dipergunakan dalam penelitian ini adalah memadukan teknik Penginderaan Jauh (PJ) dan Sistem Informasi Geografis (SIG) untuk membantu melakukan pemetaan pada lokasi.

Alat dan bahan yang digunakan adalah:

- Peta Penggunaan Lahan hasil interpretasi bulan Agustus 2013

- Google Earth Imagery Digital Globe 7/9/2012

- Perangkat lunak Arcgis 10x

- Rencana Tata Ruang Wilayah Kabupaten Bantul

- Laptop

- GPS

Proses yang digunakan dalam penelitian ini dapat digambarkan dalam diagram alir berikut ini:

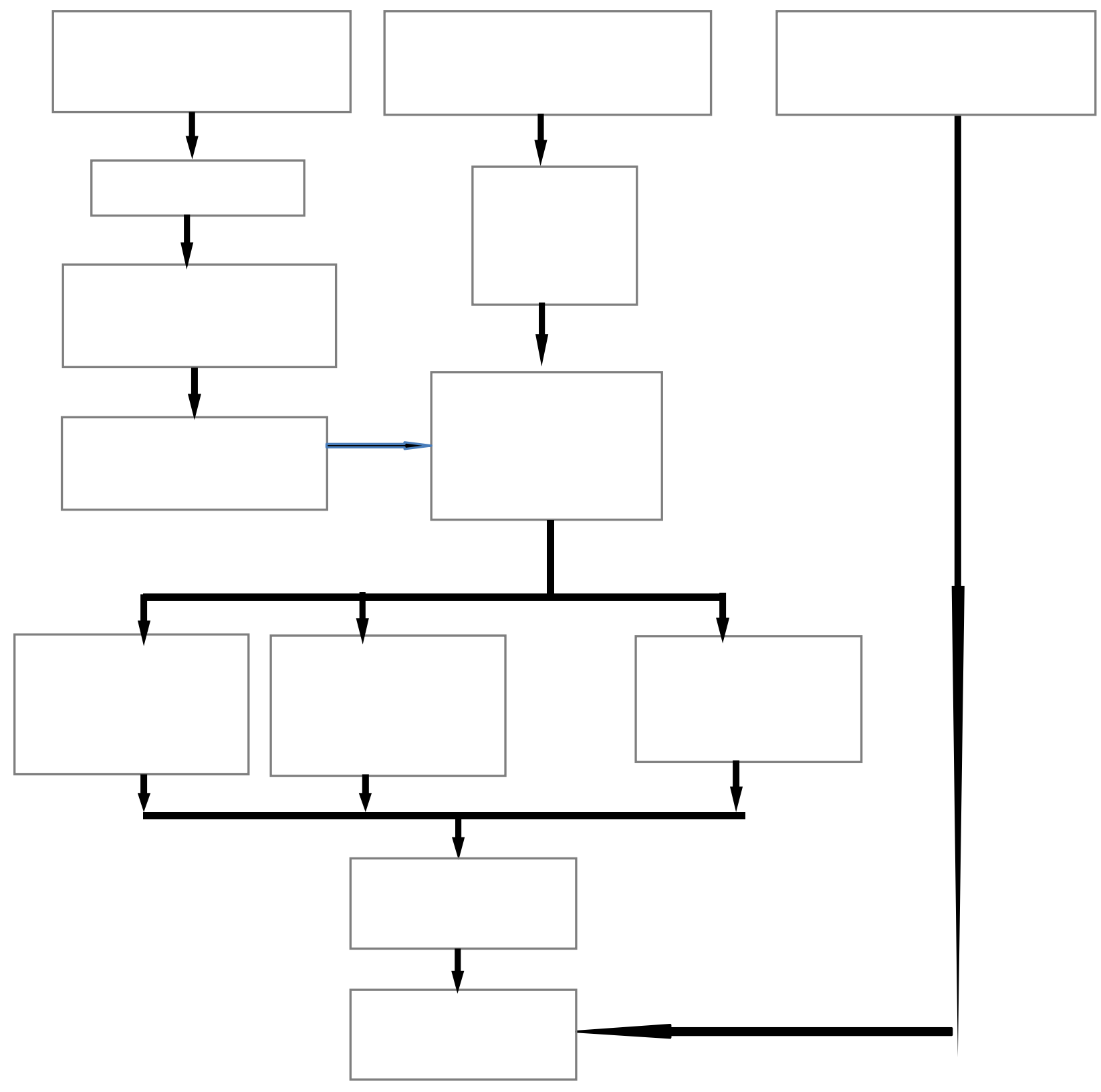




\section{Hasil dan Pembahasan}

4.1 Analisis kondisi Penggunaan lahan saat ini dan keterkaitannya dengan masa lampau dilihat dari aspek toponimi.

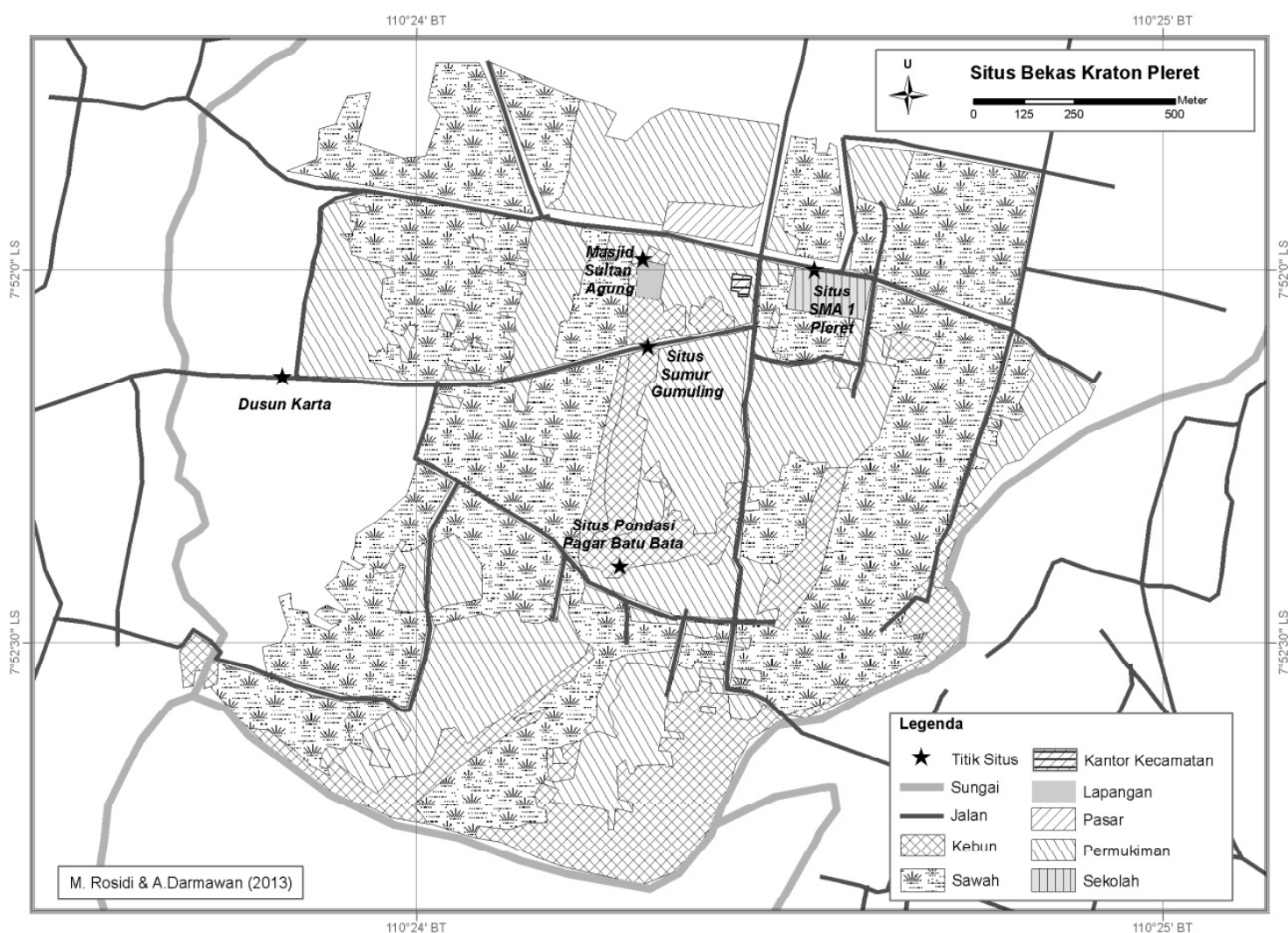

Gambar 2. Peta penggunaan lahan di sekitar daerah penelitian

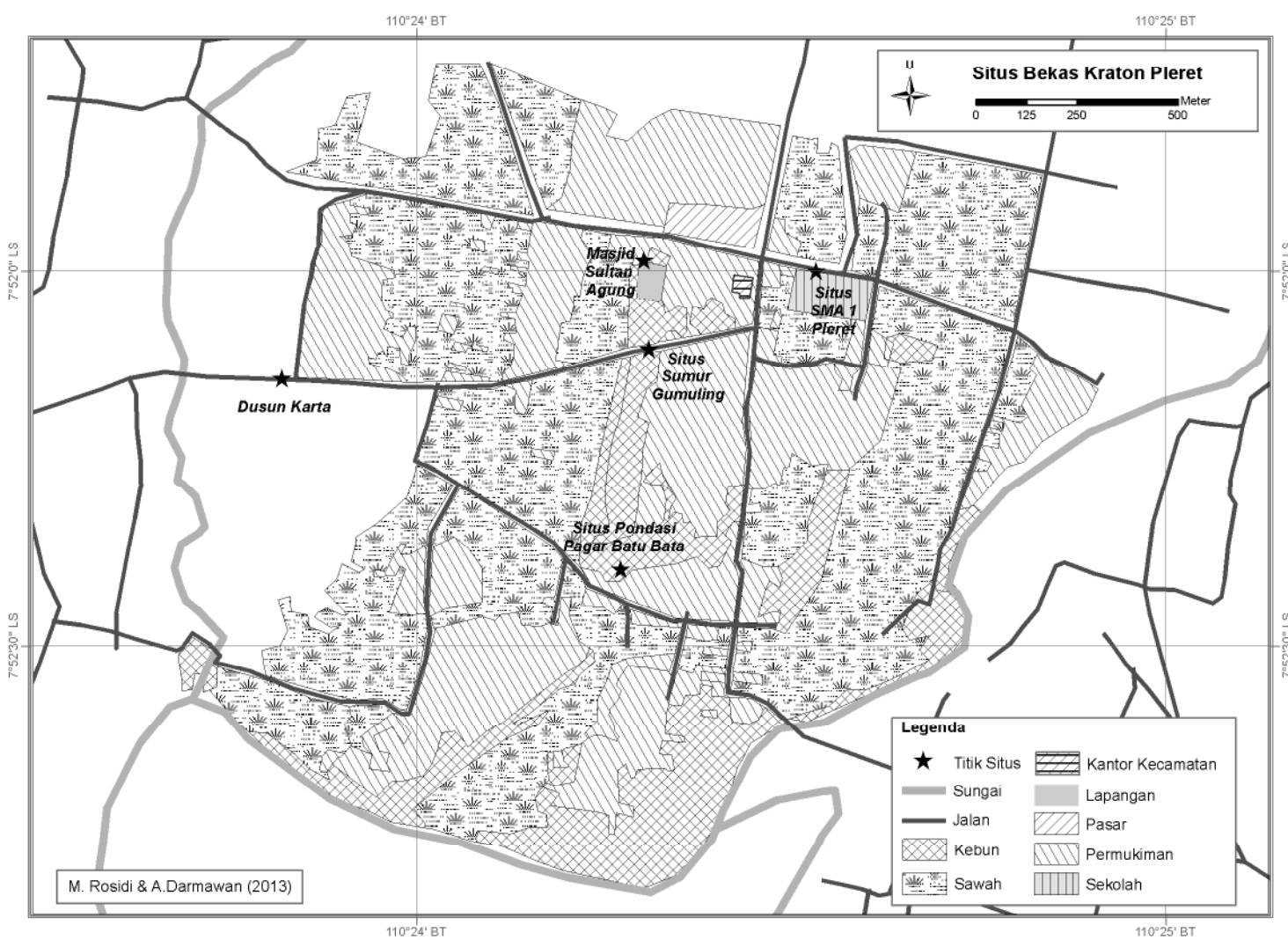

Gambar 3. Blok penting sekitar daerah penelitian 
Memperhatikan hasil interpretasi penggunaan lahan saat ini berdasarkan Google Earth Imagery Digital Globe 7/9/2012 dan ground check yang dilaksanakan pada 31 Agustus 2013, setidaknya terdapat tiga penggunaan lahan utama. Penggunaan lahan tersebut adalah sawah, kebun/pekarangan, dan permukiman. Keberadaan ketiga penggunaan lahan itu apabila dicermati membentuk pola yang simetris sebuah blok. Blok ini utamanya berada diseputaran Dusun Keputren, Kauman, Kedaton, dan terakhir di Dusun Pungkuran. Perhatikan blok dengan garis tebal pada gambar 3 diatas.

Blok penting yang digambarkan di atas ada kaitannya dengan tempat-tempat situs bekas Kraton Pleret pada masa lalu. Misalnya keberadaan Sumur Gumuling, Situs Umpak di SMA 1 Pleret, dan situs bekas pagar berbahan bata di Dusun Pungkuran. Pola penggunaan lahan nampaknya ada kaitannya dengan keberadaan situs itu. Permukiman itu berada di dalam kotak dan diselingi oleh kebun. Di luar itu terdapat areal sawah yang menjadi semacam bagian luar. Terkesan ada pola sawah mengelilingi suatu permukiman dan kebun. Mungkin pada masa lalu posisi bangunan Kraton Pleret adalah pemukiman yang sekarang, dengan pagar benteng yang mengelilinginya. Areal persawahan di sekitarnya hingga kini masih ada. Untuk lebih memperkuat praduga ini, memang diperlukan serangkaian penelitian yang lebih seksama dan juga penggalian arkeologis (ekskavasi).

Membahas situs yang telah ditemukan, situs bekas pondasi pagar berbahan bata berada di Dusun Pungkuran. Dari cerita masyarakat setempat asal nama "Pungkuran" yang dalam bahasa Indonesia berarti belakang, merupakan bekas bagian belakang dari Kraton Pleret. Diduga pada zaman dahulu posisinya berada di luar tembok pagar kraton. Sedangkan Dusun Kedaton, diduga pada zaman dahulu merupakan bagian pusat bangunan Kraton Pleret. Dugaan ini menilik dari toponimi dusun dan juga cerita yang diperoleh dari masyarakat setempat.

Lebih jauh lagi, dengan memperhatikan toponimi dan juga cerita masyarakat sekitar, ada keterkaitan satu dengan yang lainnya. Sebagai contoh keberadaan Dusun Keputren, menurut toponiminya masih ada kaitan dengan keberadaan Kedaton. Pada zaman dahulu Keputren adalah tempat tinggal putriputri raja. Sementara itu di dekat Pasar Pleret yang sekarang, terdapat dusun yang bernama Kauman. Memperhatikan toponiminya serta lokasi keberadaan yang dekat dengan sebuah masjid, kemungkinan dahulu merupakan tempat tinggal Ulama Kraton.

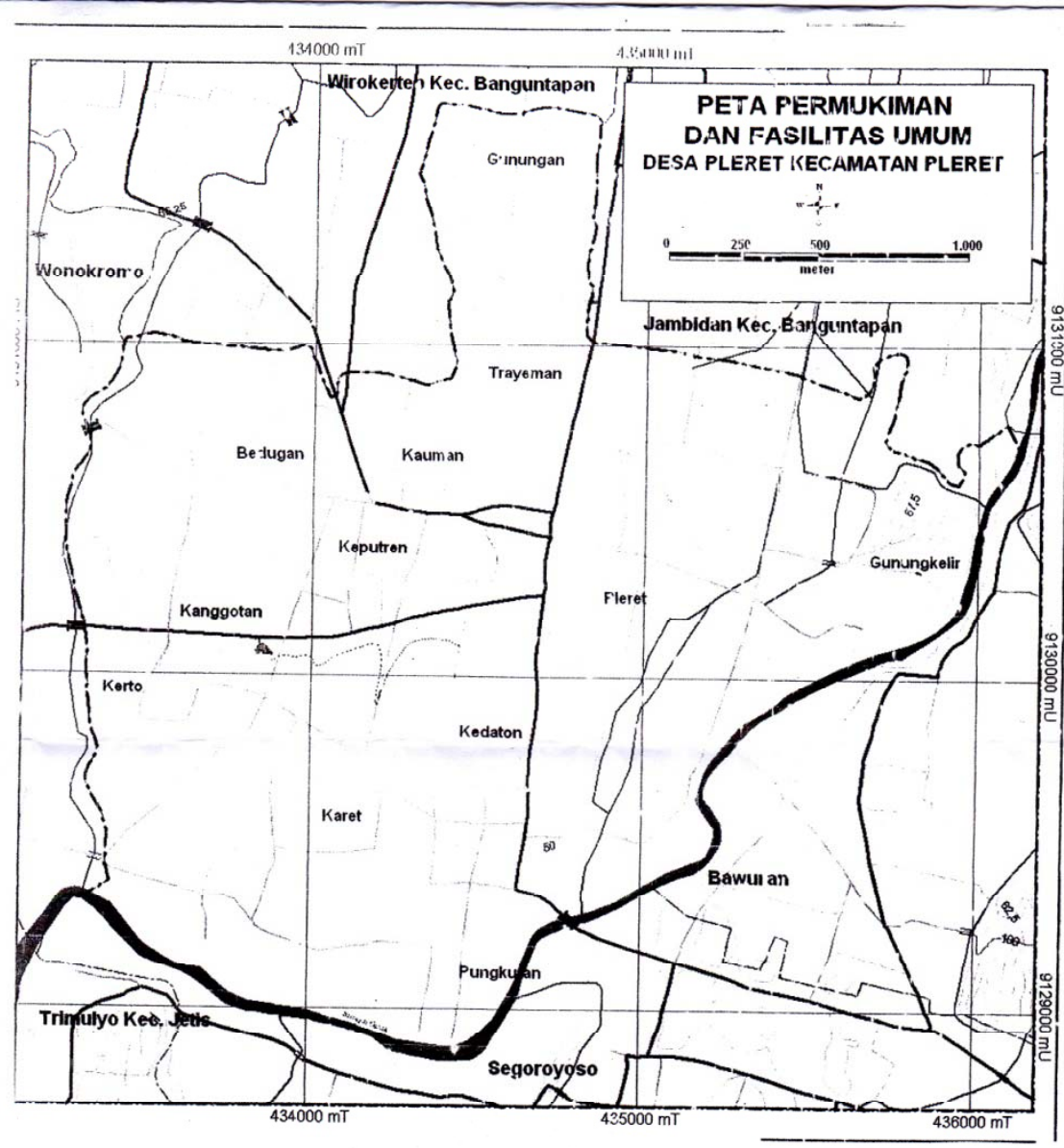

Gambar 4. Peta Pemukiman dan Fasilitas Umum Desa Pleret 
Ini diperkuat dengan memperhatikan tata ruang khas kompleks Kerajaan Islam yang ada di Jawa. Disini dapat diperbandingkan dengan arsitektur Kraton Ngayogyakarta Hadiningrat yang masih ada hingga sekarang. Di sebelah barat alun-alun kraton terdapat Masjid Gede dan juga kampung Kauman, kemudian di utara terdapat pasar sebagai pusat perdagangan penduduk. Kedaton merupakan kediaman para raja.

Dari perspektif tiga dimensi (3D) lokasi penelitian (Gambar 5) dan mengkaitkan dengan cerita dalam sejarah, bahwa pada masa Kraton Pleret terdapat lokasi laut buatan. Laut buatan itu diberi nama Segoroyoso. Saat ini Segoroyoso menjadi nama desa yang terletak di sebelah tenggara lokasi penelitian. Tepatnya di seberang selatan Kali Opak atau di sebelah selatan Dusun Kedaton dan Dusun Pungkuran.

Kalau memang benar pada masa itu ada laut buatan yang berasal dari aliran Kali Opak yang dibendung dan kini telah menjadi Desa Segoroyoso, dengan melihat perspektif tiga dimensi hal itu sangat masuk akal. Karena di sebelah timur dan selatan Kali Opak terdapat daerah perbukitan yang memungkinkan menjadi pembendung alami. Jadi air dari Kali Opak dapat terbendung karena batas alam di sisi timur dan selatan. Pada waktu itu kemungkinan input air dari arah utara kemudian outlet dari laut buatan itu berada di sisi barat mengikuti aliran Kali Opak. Jadi laut buatan itu menggenang di sisi selatan - tenggara wilayah Kraton.

4.2 Analisis spasial fungsi kawasan berdasarkan kebijakan

Kebijakan yang terkait dengan pelestarian cagar budaya di daerah ini sudah terdapat dalam Rencana Tata Ruang Wilayah Kabupaten Bantul, namun begitu belum semua cagar budaya yang ada memperoleh ketetapan dari gubernur maupun kementerian terkait. Situs-situs Kerajaan Mataram Islam di Pleret ini adalah salah satunya.

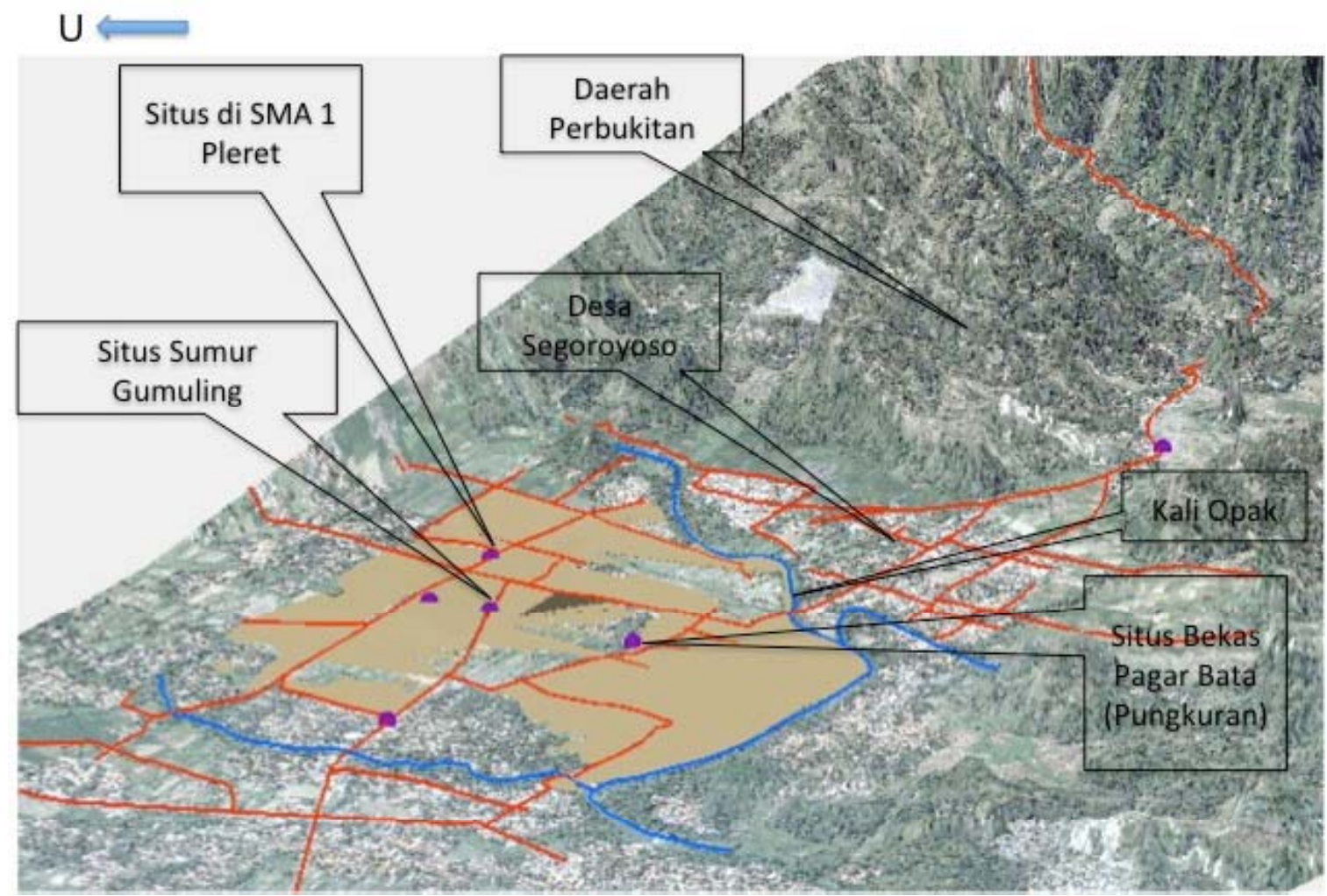

Gambar 5. Perspektif tiga dimensi lokasi penelitian 


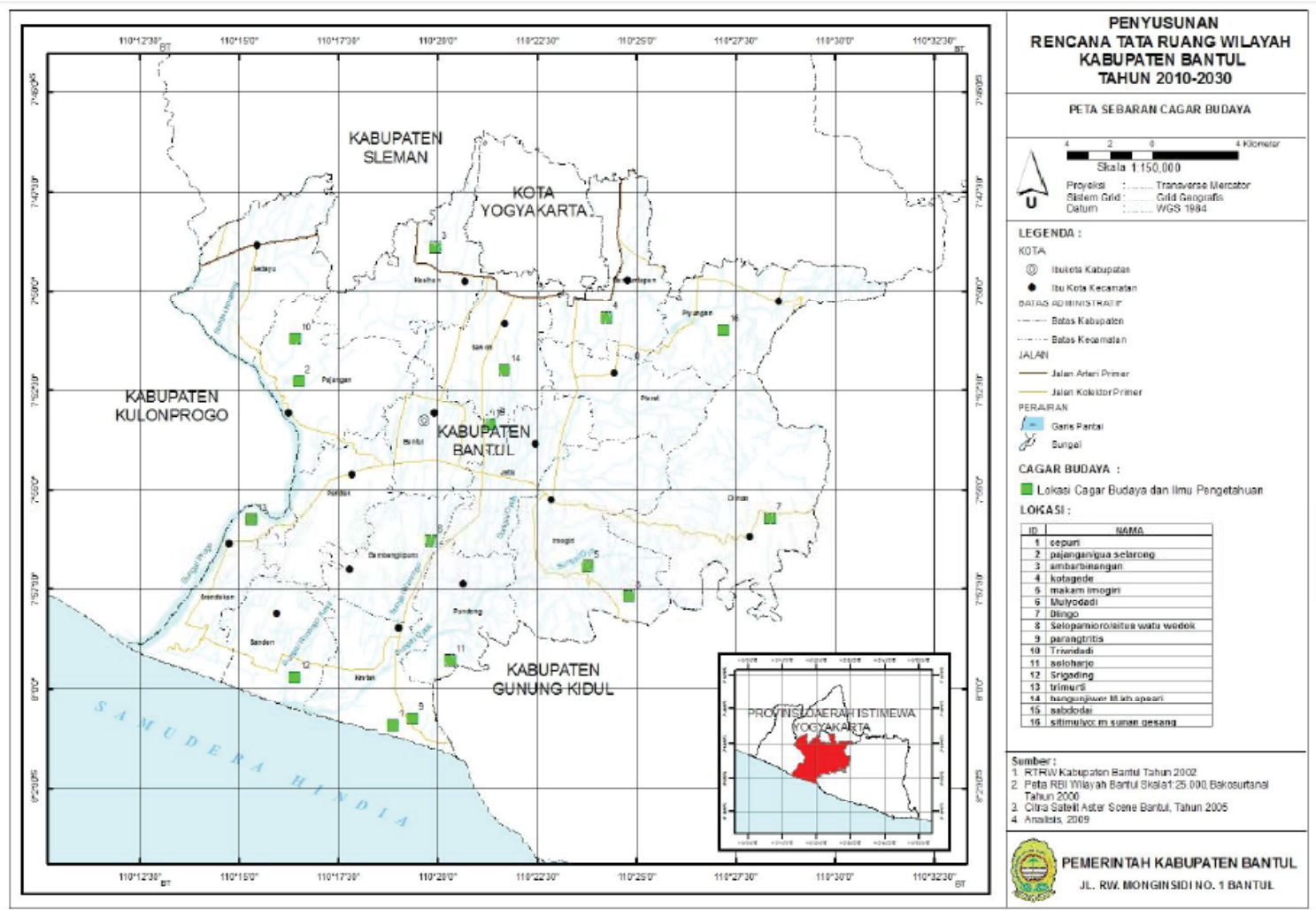

Gambar 6. Peta RTRW Kabupaten Bantul 2010-2030
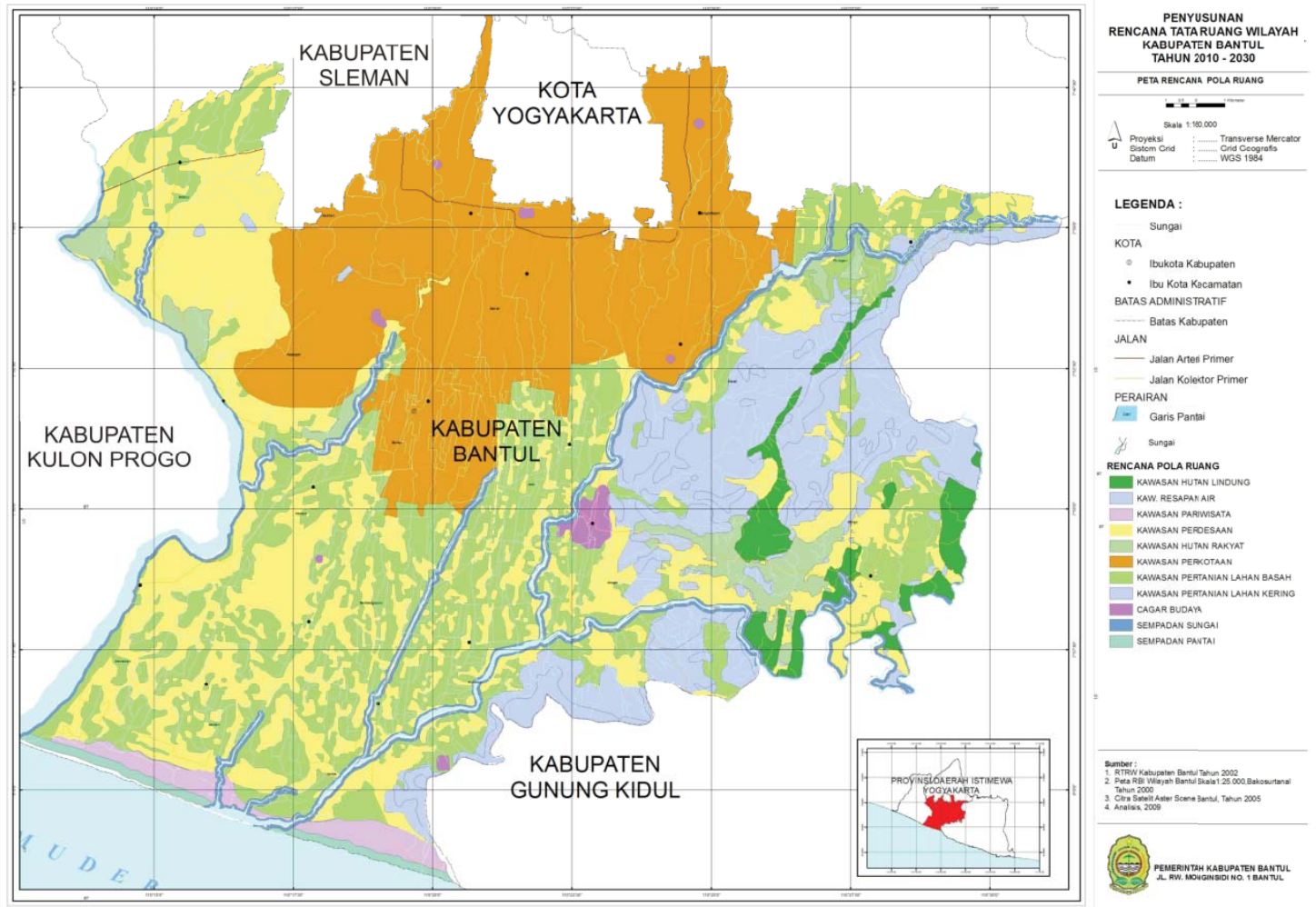

LEGENDA :

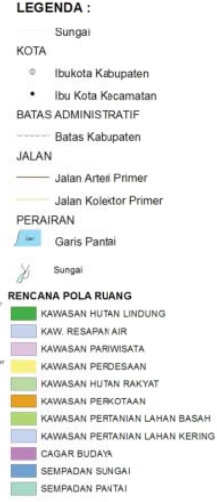

Gambar 7. Peta RTRW Kabupaten Bantul 2010-2030

Dilihat dari rencana pola ruang dalam Rencana Tata Ruang Wilayah Kabupaten Bantul, kawasan situs Kerajaan Mataram Islam tersebut direncakan menjadi kawasan perkotaan. Kawasan perkotaan berasosiasi dengan wilayah permukiman, perdagangan, dan perkantoran. Perubahan penggunaan lahan menjadi permukiman dan perdagangan di daerah tersebut tentunya akan sangat cepat mengingat meningkatnya kebutuhan ruang dengan bertambahnya jumlah penduduk. Jika kebutuhan ruang tersebut tidak dikendalikan maka kawasan-kawasan yang berpotensi merupakan bekas peninggalan kerajaan di masa 
lampau akan hilang. Hal ini akan sangat merugikan bagi negara dan kepentingan ilmu pengetahuan karena akan kehilangan khazanah kekayaan sejarah bangsa, dalam hal ini adalah bukti otentik Kerajaan Mataram Islam. Oleh karena itu diperlukan kabijakan khusus daerah ini sehingga penggalian informasi dari situssitus kerajaan bisa terus berjalan tanpa harus terganjal dengan kebutuhan dan regulasi sektor lainnya.

\section{Rekomendasi}

Mempelajari sejarah tentunya berkaitan dengan waktu yang tidak pendek. Perpindahan dari satu lokasi ke lokasi lain Kerajaan Mataram Islam ini dalam aspek keruangan tentunya berkaitan dengan

\section{Daftar Pustaka}

Adrisijanti, Inajati. 2000. Arkeologi Perkotaan Mataram Islam. Jendela. Yogyakarta.

Bappeda, 2010, RencanaTata Ruang Wilayah, Kab. Bantul.

Graaf, H.J. de. 1987. Disintegrasi Mataram di Bawah Mangkurat I. Grafitipers. Jakarta. kondisi pada waktu itu dan juga strategi kerajaan pada waktu itu pula. Hal tersebut dapat menjadi pelajaran dalam pemanfaatan ruang saat ini sehingga kesalahankesalahan masa lalu dapat diminimalisir, misalnya dari aspek resiko bencana maupun aspek dibidang pertanian dan permukiman.

Keberlanjutan penemuan beberapa situs terkait dengan Kerajaan Mataram Islam di Pleret dan sekitarnya yang telah dilindungi oleh pemerintah daerah setempat. Kedepan diharapkan tidak hanya pada skala titik namun dapat juga dilakukan zonasi pada skala kawasan, dan hal ini dapat lebih optimal dengan menggunakan teknologi Penginderaan Jauh (Inderaja) dan Sistem Informasi Geografis (SIG). 